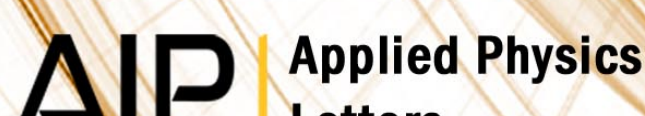 \\ Letters
}

\section{Surface band bending and electron affinity as a function of hole accumulation density in surface conducting diamond}

M. T. Edmonds, C. I. Pakes, S. Mammadov, W. Zhang, A. Tadich et al.

Citation: Appl. Phys. Lett. 98, 102101 (2011); doi: 10.1063/1.3561760

View online: http://dx.doi.org/10.1063/1.3561760

View Table of Contents: http://apl.aip.org/resource/1/APPLAB/v98/i10

Published by the American Institute of Physics.

\section{Related Articles}

Band alignment of vanadium oxide as an interlayer in a hafnium oxide-silicon gate stack structure J. Appl. Phys. 112, 084105 (2012)

Local density of states analysis using Bader decomposition for N2 and CO2 adsorbed on $\mathrm{Pt}(110)-(1 \times 2)$ electrodes

J. Chem. Phys. 137, 164705 (2012)

Hard x-ray photoelectron spectroscopy study on band alignment at poly(3,4ethylenedioxythiophene):poly(styrenesulfonate)/ZnO interface

APL: Org. Electron. Photonics 5, 237 (2012)

Fermi-level depinning at the metal-germanium interface by the formation of epitaxial nickel digermanide $\mathrm{NiGe} 2$ using pulsed laser anneal

Appl. Phys. Lett. 101, 172103 (2012)

Hard x-ray photoelectron spectroscopy study on band alignment at poly(3,4-

ethylenedioxythiophene):poly(styrenesulfonate)/ZnO interface

Appl. Phys. Lett. 101, 173303 (2012)

\section{Additional information on Appl. Phys. Lett.}

Journal Homepage: http://apl.aip.org/

Journal Information: http://apl.aip.org/about/about_the_journal

Top downloads: http://apl.aip.org/features/most_downloaded

Information for Authors: http://apl.aip.org/authors

\section{ADVERTISEMENT}
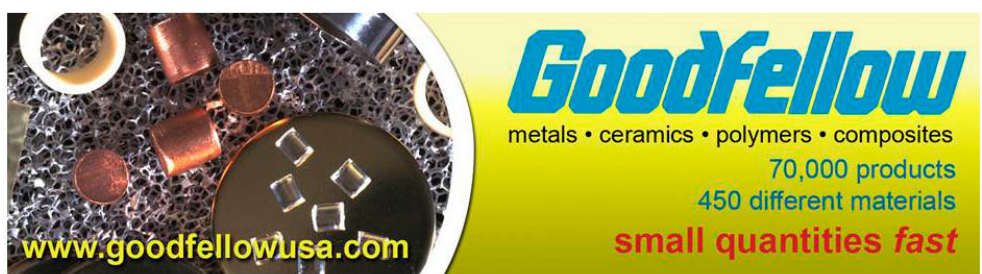


\title{
Surface band bending and electron affinity as a function of hole accumulation density in surface conducting diamond
}

\author{
M. T. Edmonds, ${ }^{1, a)}$ C. I. Pakes, ${ }^{1}$ S. Mammadov, ${ }^{2}$ W. Zhang, ${ }^{2}$ A. Tadich, ${ }^{1,3}$ J. Ristein, ${ }^{2}$ and \\ L. Ley ${ }^{2}$ \\ ${ }^{1}$ Department of Physics, La Trobe University, Victoria 3086, Australia \\ ${ }^{2}$ Technical Physics, University of Erlangen, Erwin-Rommel-Str 1, 91058 Erlangen, Germany \\ ${ }^{3}$ Australian Synchrotron, Clayton, Victoria 3168, Australia
}

(Received 23 December 2010; accepted 14 February 2011; published online 7 March 2011)

\begin{abstract}
Simultaneous measurements of work function $(\phi)$ and $\mathrm{C} 1 s$ core level shift were employed to determine the change in electron affinity $(\chi)$ and band bending as a function of hole sheet density on $\mathrm{H}$-terminated diamond for atmospheric and fullerene $\left(\mathrm{C}_{60} \mathrm{~F}_{48}\right)$ induced surface conductivity. Contrary to earlier investigations, it is shown that changes in work function do not reflect variations in the position of the surface Fermi level in response to surface transfer doping. Instead, with a transition from -0.96 to $-0.33 \mathrm{eV}, \chi$ accounts for a significant amount of the change in $\phi$ for hole densities between $5 \times 10^{8}$ and $4 \times 10^{13} \mathrm{~cm}^{-2}$. (C) 2011 American Institute of Physics.
\end{abstract}

[doi:10.1063/1.3561760]

Diamond with a band gap of $5.47 \mathrm{eV}$ is an insulator in its undoped state; however when the surface is hydrogen terminated a $p$-type surface conductivity (SC) is induced upon exposure to atmospheric conditions or synthetic surface adsorbates. $^{1-3}$ This kind of SC is favored by the negative electron affinity (NEA), $\chi$, of H-terminated diamond. ${ }^{4}$ The NEA lowers the ionization potential of diamond, $I=E_{G A P}$ $+\chi$, so that surface adsorbates with sufficiently high electron affinity promote charge transfer of electrons from the diamond valence band into the lowest unoccupied molecular orbital of the adsorbate layer leaving holes in the diamond valence band behind; this is known as surface transfer doping. ${ }^{5}$ The holes give rise to an upward band bending and a corresponding shift in surface Fermi level position and the formation of a hole accumulation layer confined to within several nanometers to hundreds of nm of the surface depending on the charge density.

Understanding the behavior of the electronic properties of H-terminated diamond in response to surface transfer doping is of fundamental importance to the development of nano-electronic devices on this platform. Significant conflict in both experimental and theoretical data exists over the position of the surface Fermi level $\left(\mathrm{E}_{\mathrm{F}}\right)$ relative to the valence band maximum (VBM) after charge transfer, with reports of the Fermi level residing in the band gap ${ }^{6}$ and deep within the valence band. $^{7-10}$ In particular, the studies in Refs. 8 and 9 relied on work function $(\phi)$ measurements alone to deduce changes in $\mathrm{E}_{\mathrm{F}}$ and did not consider changes in the surface dipole layer which would also contribute to variations in $\phi$. In this letter we present simultaneous measurements of work function and Fermi level shift in the H-terminated diamond surface as a function of hole sheet density for atmospheric and fluorinated fullerene $\left(\mathrm{C}_{60} \mathrm{~F}_{48}\right)$ induced $\mathrm{SC}$. We show that surface transfer doping is accompanied by a significant increase in $\chi$ of up to $0.63 \mathrm{eV}$, whereas the corresponding shift in Fermi energy amounts to $0.82 \mathrm{eV}$.

The natural type IIa diamond (100) single crystal used in this experiment was cleaned and H-terminated using the

${ }^{a)}$ Electronic mail: mtedmonds@students.latrobe.edu.au. techniques described by Riedel et al. ${ }^{11}$ The $\mathrm{C}_{60} \mathrm{~F}_{48}$ used in this experiment was sourced commercially (Term USA). Atmospheric SC was induced by exposure to water immediately after hydrogenation in order to accelerate the formation of $p$-type SC. The sample was then mounted in the configuration adopted by Strobel et al. ${ }^{3}$ to enable in situ conductivity measurements. After introduction into vacuum, measurements were performed as a function of annealing to remove the atmosphere induced SC. After the sample was in a low conductance state, SC was again induced in incremental steps by evaporating $\mathrm{C}_{60} \mathrm{~F}_{48}$ onto the still $\mathrm{H}$-terminated surface. All experiments were performed in interconnected ultrahigh vacuum chambers, with photoemission and Kelvin probe measurements performed in the main analysis chamber $\left(\mathrm{p}<10^{-9}\right.$ mbar), while evaporation of $\mathrm{C}_{60} \mathrm{~F}_{48}$ and conductivity measurements were performed in a separate chamber $\left(\mathrm{p}<10^{-8}\right.$ mbar). $\mathrm{C}_{60} \mathrm{~F}_{48}$ was deposited by sublimation from a quartz crucible, using a quartz crystal monitor as a guide to deposition rate. C $1 s$ X-ray photoelectron spectroscopy (XPS) spectra were used to accurately evaluate $\mathrm{C}_{60} \mathrm{~F}_{48}$ coverages in the manner described by Strobel et $a l^{3}$

The electron affinity $\chi$ is defined as the energy difference between the vacuum level $\mathrm{E}_{\mathrm{VAC}}$ and the conduction band minimum $\mathrm{E}_{\mathrm{CBM}} \cdot \chi$ can be expressed as $\chi=\phi+\left(\mathrm{E}_{\mathrm{F}}-\mathrm{E}_{\mathrm{VBM}}\right)$ $-\mathrm{E}_{\mathrm{GAP}}$, and can thus be determined from measurements of the work function, $\phi$, and Fermi level, $\mathrm{E}_{\mathrm{F}}$, with respect to the VBM, $\mathrm{E}_{\mathrm{VBM}}$. Changes in $\mathrm{E}_{\mathrm{F}}$ in response to surface transfer doping, were determined by monitoring changes in the $\mathrm{C} 1 \mathrm{~s}$ core level binding energy of diamond employing XPS with a monochromatized $\mathrm{Al} K \alpha$ source $(1486.6 \mathrm{eV})$ and an overall resolution of $0.7 \mathrm{eV}$. All spectra were calibrated using $\mathrm{Au}$ in electrical contact with the diamond sample and setting the Au $4 f_{7 / 2}$ binding energy to $84.00 \mathrm{eV}$. During XPS measurements it was verified that no charging of the diamond sample had taken place, particularly in the absence of high SC. The spectra were corrected by subtracting a background using the Shirley method, ${ }^{12}$ then fitted with Voigt functions with the Lorentz width $\Gamma_{\mathrm{L}}$ fixed at $0.15 \mathrm{eV}$ to reflect the lifetime of the $\mathrm{C} 1 \mathrm{~s}$ core hole. ${ }^{13}$ For each spectrum the diamond $\mathrm{C} 1 \mathrm{~s}$ peak was fitted with a dominant bulk component and a small 
hydrocarbon component shifted by $+0.5 \mathrm{eV}$ with respect to the bulk core level. ${ }^{13}$ Shifts in Fermi level were determined by the measured shift in the diamond bulk peak with an uncertainty of $\pm 0.02 \mathrm{eV}$. In order to determine $\mathrm{E}_{\mathrm{F}}-\mathrm{E}_{\mathrm{VBM}}$ from the $\mathrm{C} 1 s$ binding energy we take the fixed energy separation of the VBM to the $\mathrm{C} 1 s$ core level to be $283.9 \pm 0.1 \mathrm{eV}$ as reported by Maier et al. ${ }^{6}$

For hole sheet densities above $10^{13} \mathrm{~cm}^{-2}$ band bending occurs on a length scale significantly smaller than the effective electron mean free path of $1.4 \mathrm{~nm} .^{7,14}$ The convolution of the $\mathrm{C} 1 s$ line with the band profile leads to a broadening of the Gaussian component from $\Gamma_{\mathrm{G}}=0.75 \mathrm{eV} \quad(p=5$ $\left.\times 10^{8} \mathrm{~cm}^{-2}\right)$ to $\Gamma_{\mathrm{G}}=0.9 \mathrm{eV}\left(p=4.1 \times 10^{13} \mathrm{~cm}^{-2}\right)$. Also, for hole sheet densities above $10^{13} \mathrm{~cm}^{-2}$ the measured $\mathrm{C} 1 \mathrm{~s}$ binding energy does not represent that right at the surface. To determine the true $E_{F}-E_{V B M}$ at the surface we modeled the Gaussian component of the line profile by taking the depth dependent variation in binding energy and the effective electron mean free path into account. From this model, energy corrections between the average (i.e., experimentally observed) line position and the true surface position were derived. The surface band profile was approximated by a linear profile with a slope that corresponds to the surface electric field which is uniquely related to the total hole sheet density. ${ }^{14}$ For the highest hole sheet density of 4.1 $\times 10^{13} \mathrm{~cm}^{-2}$ the correction amounts to $0.45 \mathrm{eV}$. In Fig. 1 the uncorrected values for $E_{F}-E_{V B M}$ are plotted along with the corrected values, whereas Fig. 2 contains only corrected values.

The changes in $\phi$ were determined using the Kelvin method by measuring the contact potential difference (CPD) of the diamond surface relative to a gold reference of known work function (determined in situ by total photoelectron yield spectroscopy). The error in measurement was \pm 30 $\mathrm{meV}$ for CPD and $\pm 20 \mathrm{meV}$ for the work function of the gold reference. The uncertainty of $\pm 0.1 \mathrm{eV}$ in the energy separation between the $\mathrm{C} 1 s$ core level and VBM mentioned above remains as a systematic error in $\chi$. The twodimensional sheet conductivity $\sigma_{\square}$ was obtained through in situ conductance measurements in the manner described by Strobel et $a l^{3}$ The areal hole density is given by $p=\sigma_{\square} / e \mu$ with the average mobility of the hole sheet in diamond taken to be $\mu=70 \mathrm{~cm}^{2} \mathrm{~V}^{-1} \mathrm{~s}^{-1} ;{ }^{15}$ this mobility value has been confirmed for the sample used in the present experiment. ${ }^{16}$

Measurements related to atmosphere induced SC for the as-prepared sample and after annealing in vacuum to temperatures of up to $250{ }^{\circ} \mathrm{C}$ are shown in Fig. 1(a). In Fig. 1(a) $\mathrm{E}_{\mathrm{F}}-\mathrm{E}_{\mathrm{VBM}}$, the work function $\phi$, and the electron affinity $\chi$ are plotted versus the areal hole density $p$. For areal hole densities between $5 \times 10^{8}$ and $2.6 \times 10^{13} \mathrm{~cm}^{-2}$ the work function increases by $\Delta \phi=1.12 \mathrm{eV}$. Only $0.67 \mathrm{eV}$ of this variation can be attributed to an increase in upward band bending corresponding to a reduction in $\mathrm{C} 1 s$ binding energy and hence $\left(\mathrm{E}_{\mathrm{F}}-\mathrm{E}_{\mathrm{VBM}}\right)$ of $0.67 \mathrm{eV}$. The remainder reflects a significant increase in electron affinity of $\Delta \chi$ $=0.45 \mathrm{eV}$.

In Fig. 1(b) $\mathrm{E}_{\mathrm{F}}-\mathrm{E}_{\mathrm{VBM}}$, the work function $\phi$, and the electron affinity $\chi$ are plotted versus $\mathrm{C}_{60} \mathrm{~F}_{48}$ coverage with the areal hole density, $p$, given at each data point. $\mathrm{C}_{60} \mathrm{~F}_{48}$ evaporation was commenced at a low surface conductance of $5.6 \times 10^{-9} \mathrm{~S}$; then all measurements alluded to above were made after each evaporation step. The hole concentration (a)

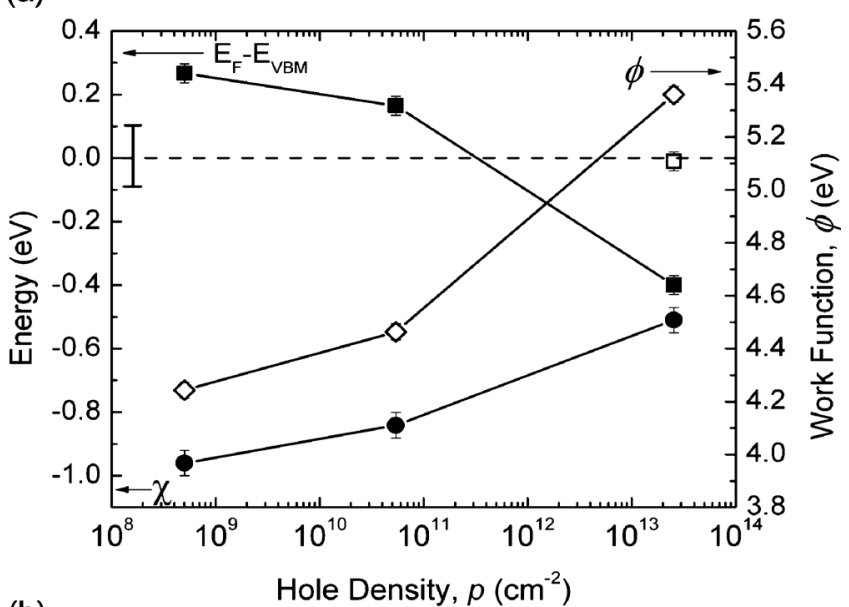

(b)

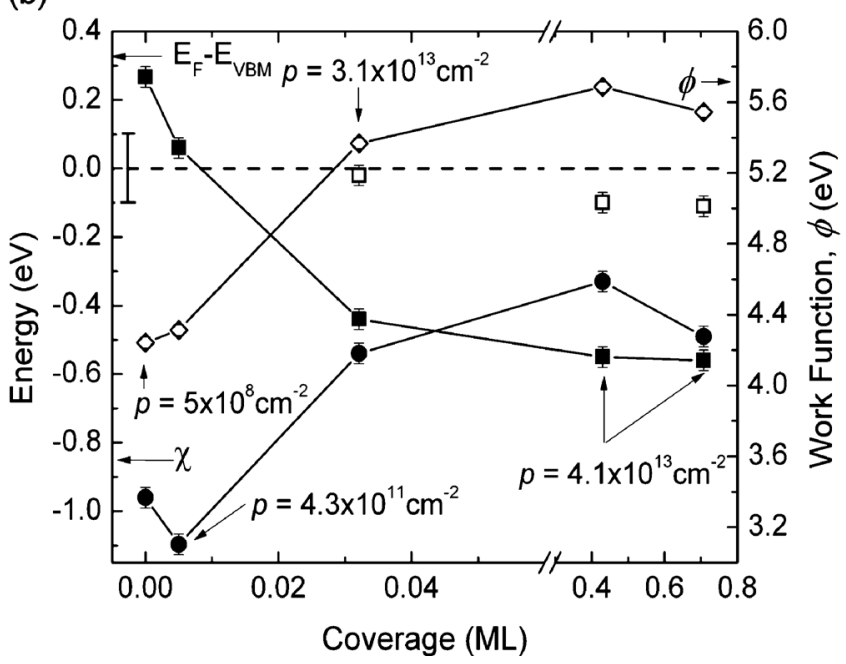

FIG. 1. $\mathrm{E}_{\mathrm{F}}-\mathrm{E}_{\mathrm{VBM}}$ (open squares before and filled squares after $\mathrm{C} 1 \mathrm{~s}$ binding energy corrections), work function $\phi$ (open diamonds), and electron affinity $\chi$ (filled circles); (a) as a function of hole density for atmosphere induced SC, (b) as a function of coverage and hole density for $\mathrm{C}_{60} \mathrm{~F}_{48}$ induced SC. The broken line, which refers to the left hand energy scale only, represents the VBM position (see Ref. 6).

appears to saturate at $4.1 \times 10^{13} \mathrm{~cm}^{-2}$ for a coverage of 0.4 monolayers (ML) in agreement with previous reports. ${ }^{3}$ The band bending increases $\left[\left(\mathrm{E}_{\mathrm{F}}-\mathrm{E}_{\mathrm{VBM}}\right)\right.$ decreases $]$ monotonically with hole concentration and $\mathrm{E}_{\mathrm{F}}-\mathrm{E}_{\mathrm{VBM}}=-0.44 \mathrm{eV}$ for $p=3 \times 10^{13} \mathrm{~cm}^{-2}$, i.e., at the same hole concentration as for the air induced SC. For higher hole concentrations, $\mathrm{E}_{\mathrm{F}}$ moves further into the valence band and ends up $0.55 \mathrm{eV}$ below the VBM for $p=4.1 \times 10^{13} \mathrm{~cm}^{-2}$. The work function changes also monotonically over the same range of hole concentrations and increases by a total of $\Delta \phi=1.45 \mathrm{eV}$. Resulting in a maximum variation in $\chi$ of $\Delta \chi=0.63 \mathrm{eV}$.

The change in work function measured for atmosphere induced SC is consistent with previously reported values. The response of the work function to the deposition of $\mathrm{C}_{60} \mathrm{~F}_{48}$ is similar but with a higher overall increase in keeping with the higher hole density achieved by this method. In both cases, the changes in band bending with hole sheet density are accompanied by a significant increase in electron affinity of up to $0.63 \mathrm{eV}$.

The origin of the change in $\chi$ is best understood with the help of Fig. 2(a). Here we have plotted schematically the electron potential diagram of $\mathrm{H}$-terminated diamond for both low and high $\mathrm{C}_{60} \mathrm{~F}_{48}$ coverage. The origin of the potential 
(a)

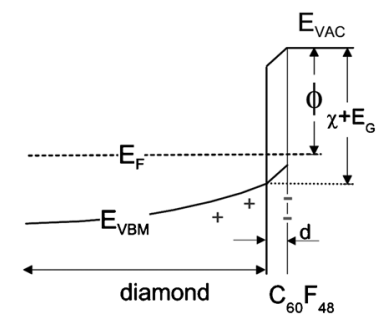

(b)

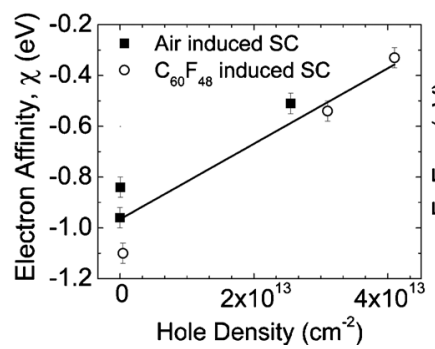

(c)

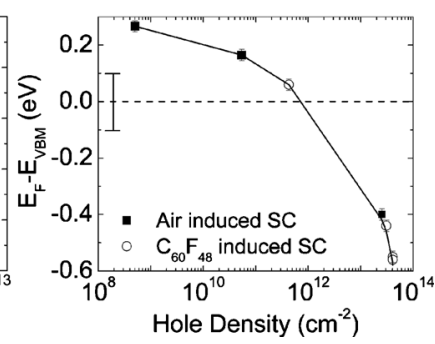

FIG. 2. (a) Schematic electron potential profile (band diagram) of $\mathrm{H}$-terminated diamond transfer doped by $\mathrm{C}_{60} \mathrm{~F}_{48}$; left panel: very low coverage, right panel: coverage corresponding to saturated hole density. (b) Electron affinity (data points) as a function of hole sheet density. Solid line is a linear fit of the data. (c) $E_{F}-E_{V B M}$ as a function of hole sheet density.

variation across the diamond-acceptor interface lies in the charges that result from the transfer doping process: positive holes in diamond and electrons in the $\mathrm{C}_{60} \mathrm{~F}_{48}$ layer as indicated in the figure. The potential in diamond follows the VBM and is continued with constant slope over a narrow, charge-free region of thickness $d$ into the $\mathrm{C}_{60} \mathrm{~F}_{48}$ layer. The width $d$ is the separation between the locus of negative charge in the $\mathrm{C}_{60} \mathrm{~F}_{48}$ layer and the diamond surface. Outside the charged $\mathrm{C}_{60} \mathrm{~F}_{48}$ layer the field is zero again and hence the potential constant. Similarly, the vacuum level $\mathrm{E}_{\mathrm{VAC}}$ also follows the potential as drawn. The potential drop $\Delta U$ across the charge free region increases with the amount of transferred charge and is responsible for the increase in $\chi$ which is the difference between the VBM at the interface and the vacuum level $\mathrm{E}_{\mathrm{VAC}}$ outside the $\mathrm{C}_{60} \mathrm{~F}_{48}$ layer. The potential drop $e \Delta U$ which equals $\Delta \chi$ follows in the simplest electrostatic approximation from the capacitor equation. With this approximation, $\Delta \chi$ is expected to scale linearly with the areal charge density, an expectation born out by Fig. 2(b) where $\Delta \chi$ is plotted versus $p$ on a linear scale. Linear regression yields for the charge-free distance, $d=\varepsilon \cdot 0.17 \mathrm{~nm}$, where $\varepsilon$ is the effective dielectric constant of the charge-free region. For $\varepsilon=2.8$ which is half way between those of diamond (5.7) and vacuum we obtain $d=0.48 \mathrm{~nm}$. This is larger than the $\mathrm{C}-\mathrm{H}$ bond length $(0.1 \mathrm{~nm})$ and about half the diameter of the $\mathrm{C}_{60} \mathrm{~F}_{48}$ molecule, hence a reasonable value.
Figure 2(c) illustrates the variation in $\mathrm{E}_{\mathrm{F}}-\mathrm{E}_{\mathrm{VBM}}$ as a function of hole sheet density for both atmosphere and $\mathrm{C}_{60} \mathrm{~F}_{48}$ induced SC, and shows that the Fermi level lies below the VBM for hole sheet densities exceeding $10^{12} \mathrm{~cm}^{-2}$, and in the band gap for lower densities, independent of the nature of the acceptors. In the present work $p=4$ $\times 10^{13} \mathrm{~cm}^{-2}$ corresponds to $\mathrm{E}_{\mathrm{F}}-\mathrm{E}_{\mathrm{VBM}}=-0.55 \mathrm{eV}$, compared to theoretical results of $-0.46 \mathrm{eV}$ for a classical model, ${ }^{14}-0.87 \mathrm{eV}$ and $-0.88 \mathrm{eV}\left(p=5 \times 10^{13} \mathrm{~cm}^{-2}\right)$, respectively, for full quantum mechanical calculations. ${ }^{7,10}$ The electron affinity of $-0.51 \mathrm{eV}$ measured here for atmosphere induced SC is in excellent agreement with the $-0.50 \mathrm{eV}$ reported by Ristein et al. ${ }^{17}$ for $\mathrm{H}$-terminated diamond in contact with an aqueous electrolyte.

In conclusion, by utilizing simultaneous measurements of work function and surface Fermi level position for surface conducting H-terminated diamond we show that the surface band bending amounts to a maximum of $0.82 \mathrm{eV}$ while at the same time the electron affinity increases by up to $0.63 \mathrm{eV}$ in response to the formation of a $p$-type accumulation layer induced in diamond by transfer doping from surface acceptors. This proves that work function measurements alone are insufficient to determine the extent of band bending in the near surface regime as a result of charge transfer. We present a model for the change in electron affinity that agrees with experiment and depends solely on the areal density of transferred charge and not on the nature of the acceptors as long as the surface coverage stays below one ML.

This work was supported by the Australian Research Council Grant No. DP0879827, and Australian Synchrotron. M.T.E. would like to thank the Technical Physics Institute at the University of Erlangen for their generous hospitality.

${ }^{1}$ M. I. Landstrass and K. V. Ravi, Appl. Phys. Lett. 55, 975 (1989).

${ }^{2}$ P. Strobel, M. Riedel, J. Ristein, and L. Ley, Nature (London) 430, 439 (2004).

${ }^{3}$ P. Strobel, M. Riedel, J. Ristein, L. Ley, and O. Boltalina, Diamond Relat. Mater. 14, 451 (2005).

${ }^{4}$ J. Cui, J. Ristein, and L. Ley, Phys. Rev. Lett. 81, 429 (1998).

${ }^{5}$ F. Maier, M. Riedel, B. Mantel, J. Ristein, and L. Ley, Phys. Rev. Lett. 85, 3472 (2000).

${ }^{6}$ F. Maier, J. Ristein, and L. Ley, Phys. Rev. B 64, 165411 (2001).

${ }^{7}$ M. T. Edmonds, C. I. Pakes, and L. Ley, Phys. Rev. B 81, 085314 (2010).

${ }^{8}$ B. Rezek, C. Sauerer, C. E. Nebel, M. Stutzmann, J. Ristein, L. Ley, E. Snidero, and P. Bergonzo, Appl. Phys. Lett. 82, 2266 (2003).

${ }^{9}$ C. I. Pakes, D. Hoxley, J. R. Rabeau, M. T. Edmonds, R. Kalish, and S. Prawer, Appl. Phys. Lett. 95, 123108 (2009).

${ }^{10}$ C. E. Nebel, B. Rezek, and A. Zrenner, Diamond Relat. Mater. 13, 2031 (2004).

${ }^{11}$ M. Riedel, J. Ristein, and L. Ley, Phys. Rev. B 69, 125338 (2004).

${ }^{12}$ D. A. Shirley, Phys. Rev. B 5, 4709 (1972).

${ }^{13}$ R. Graupner, F. Maier, J. Ristein, L. Ley, and C. Jung, Phys. Rev. B 57, 12397 (1998).

${ }^{14}$ J. Ristein, Diamond Relat. Mater. 13, 808 (2004).

${ }^{15}$ K. Hayashi, S. Yamanaka, H. Watanabe, T. Sekiguchi, H. Okushi, and K. Kajimura, J. Appl. Phys. 81, 744 (1997).

${ }^{16}$ P. Strobel, Ph.D. thesis, University of Erlangen, 2008.

${ }^{17}$ J. Ristein, W. Zhang, and L. Ley, Phys. Rev. B 78, 041602 (2008). 